\title{
Espiguetas de dois grãos no milho $\left(^{*}\right)$
}

\author{
Dr. H. C. Cutler \\ Harvard University \\ Cambridge - Mass. EE. UU.
}

\section{INDICE}

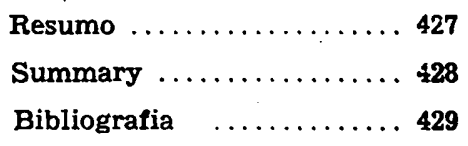

(*) O trabalho apresentado foi executado quando o autor esteve em Firacicaba, como "Fellow of the Guggenheim Foundation". O autor deseja exprimir os seus agradecimentos ao Snr. Diretor da Escola Superior de Agricultura "Luiz de Queiroz", pela permissão de trabalhar na Seção de Genética, e ao Dr. F. G. Brieger por sugestōes, como também pela permissão de usar material da sua coleção. 
A espiga típica do milho pode ser considerada como um eixo envolto por uma série de espiguetas, em pares, geralmente dispostas em filas longitudinais (Fig. 1b). Há toda evidencia de que a espiga representa uma panicula, com filotaxia normal, na qual os ramos são muito reduzidos (WEATHERWAX 1935). Suas partes correspondem às partes da espigueta do pendão (Fig. 2B; 2C). Dentro duma pequena depressão da espiga (alveolus), estáo as espiguetas gemeas, cada uma com duas flores. No milho comum, apenas a flor superior em cada espigueta se desenvolve, e os vestígios da flor mais baixa são dificilmente visiveis na espiga madura (Figs. 2B, 4B).

Espigas com espiguetas de dois grãos têm sido encontradas, frequentemente, nos Andes Centrais, e, ocasionalmente, no Brasil, mas são muito raras em outros lugares. Uma só exceçáo é a variedade chamada Country Gentleman, um milho doce, usualmente plantado nos Estados Unidos da América do Norte. A natureza dos grãos duplos nesta varièdade foi estudada por vários autores (KEMPTON 1913, STEWART, 1915, WEATHERWAX 1916, BONNETT 1940). A flor mais baixa sempre se desenvolve depois da superior (Figs. 2A, 3A), e seus grăos săo comprimidos entre os já desenvolvidös, empurrando estes para fora do alinhamento. As vezes, o segundo grăo se desenvolve com tanto atraso que há pouco espaço para êle na esjiga, $€$ cresce com um embriăo menor, podendo ter o endosperma reduzido. Geralmente, é difícil distinguif filas distintas numa espiga madura de milho Country Gentleman, mas quando os grãos agrupados săo removidos, os alvéolos aparecem dispostos em ordem. raro os pequenos grăos inferiores introduzirem-se uniformemente entre as fllas das flores superiores, formando, assim, pares sucessivos de tHlas de grãos pequenos e grandes. Quando há polen apenas num curto espaço de tempo, somente em algumas espiguetas haverá dois grãos, haverá algumas espiguetas com grãos só nas flores superiores, enquanto que, em baixo, na direção da base da espiga, figurarão espiguetas com um só grăo nas flores inferiores, o que se desenvolve posteriormente.

Uma espiga com espiguetas de dois grãos, produz um número maior de sementes do que outra tendo apenas espiguetas de um grăo, mas, tais sementes săo menores e mais fracas, sendo o tamanho menor devido a menor quantidade de endosperna. O embriáo só é ligeiramente reduzido, em tamanho e como contém a maior parte dos óleos e sais minerais, um aumento do número de embrióes resulta em maior rendimento de cleos e sais minerais por espiga. Nøo é de crer que um maior 


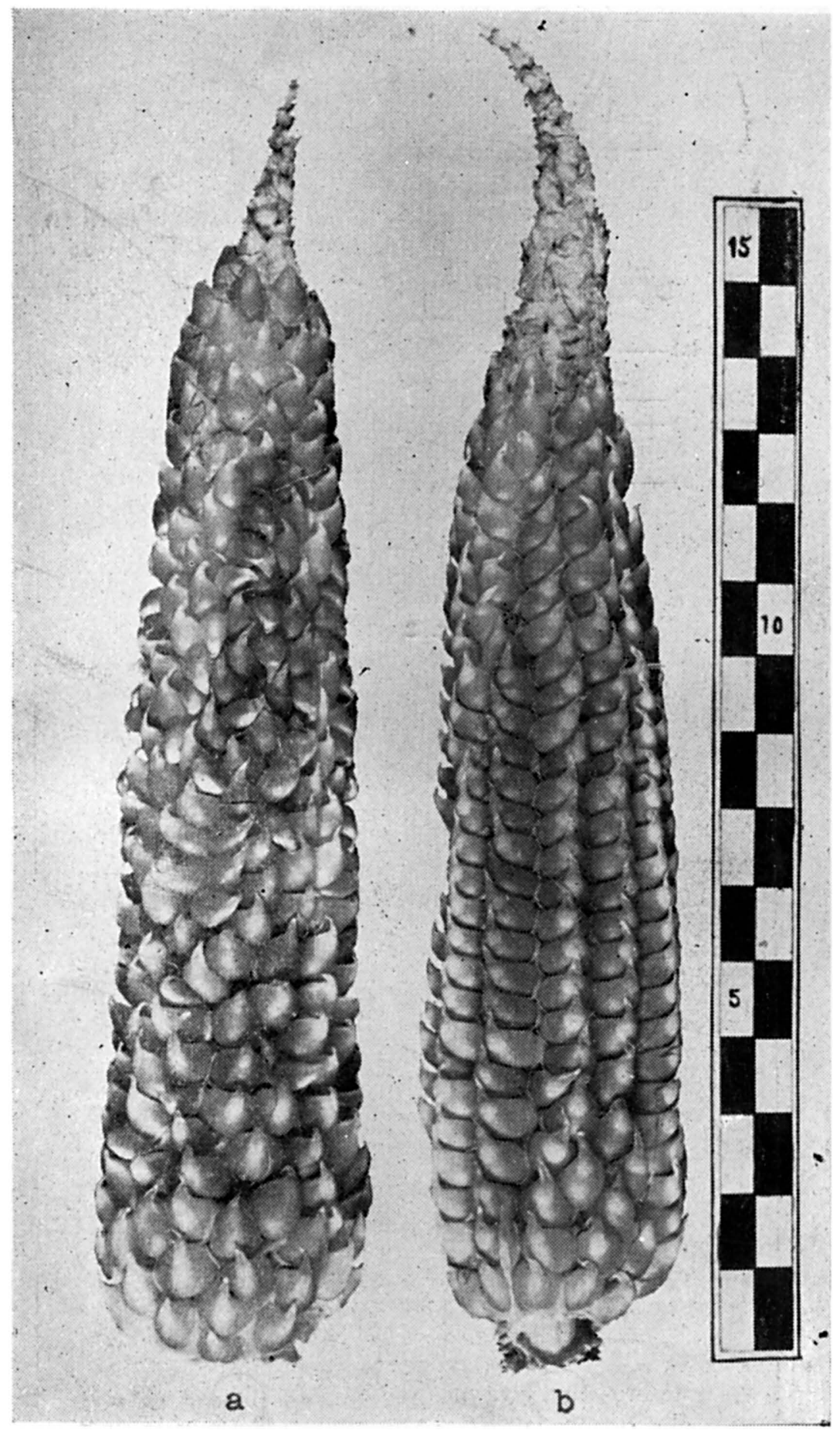



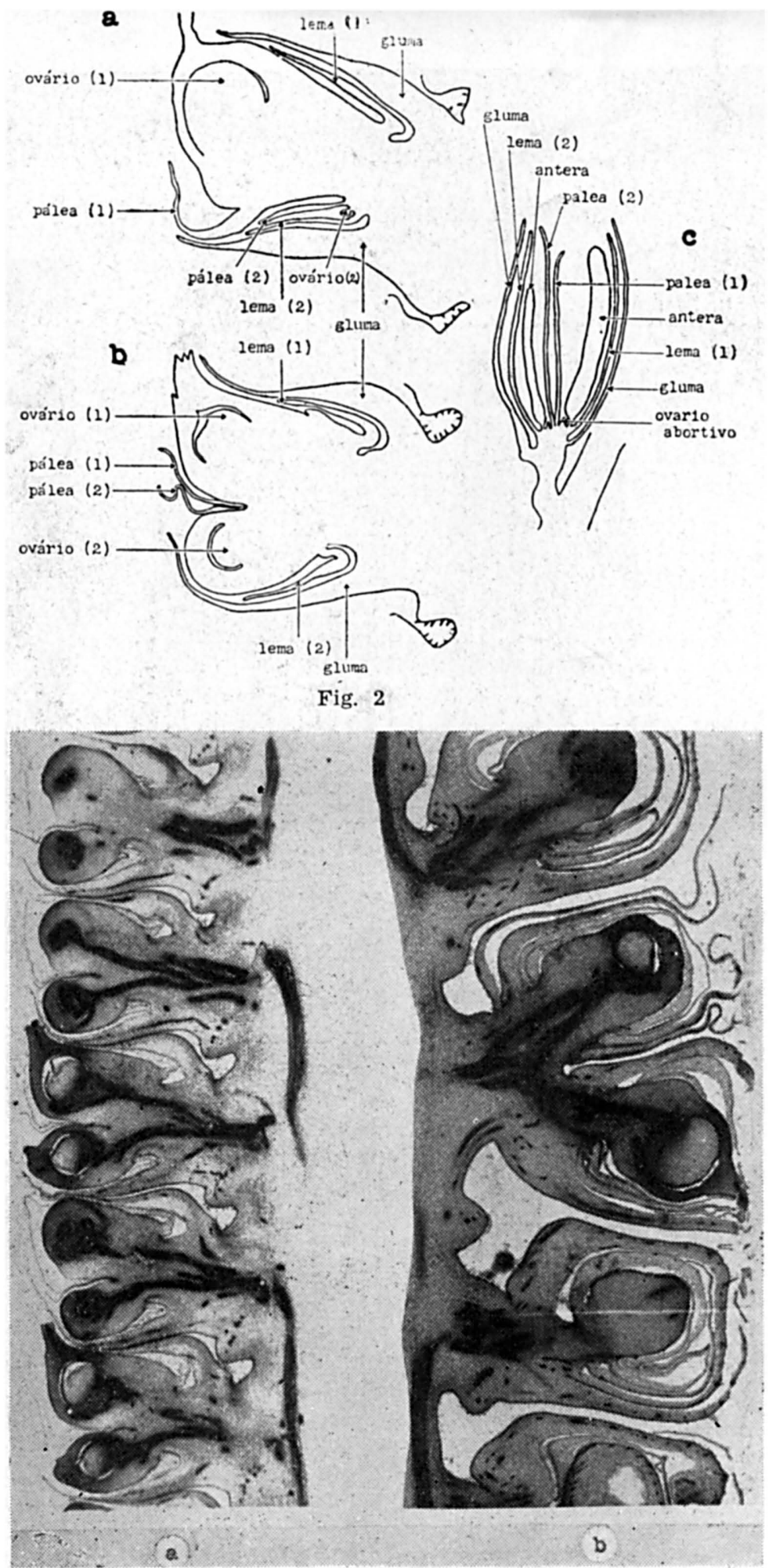

Fig. 3 

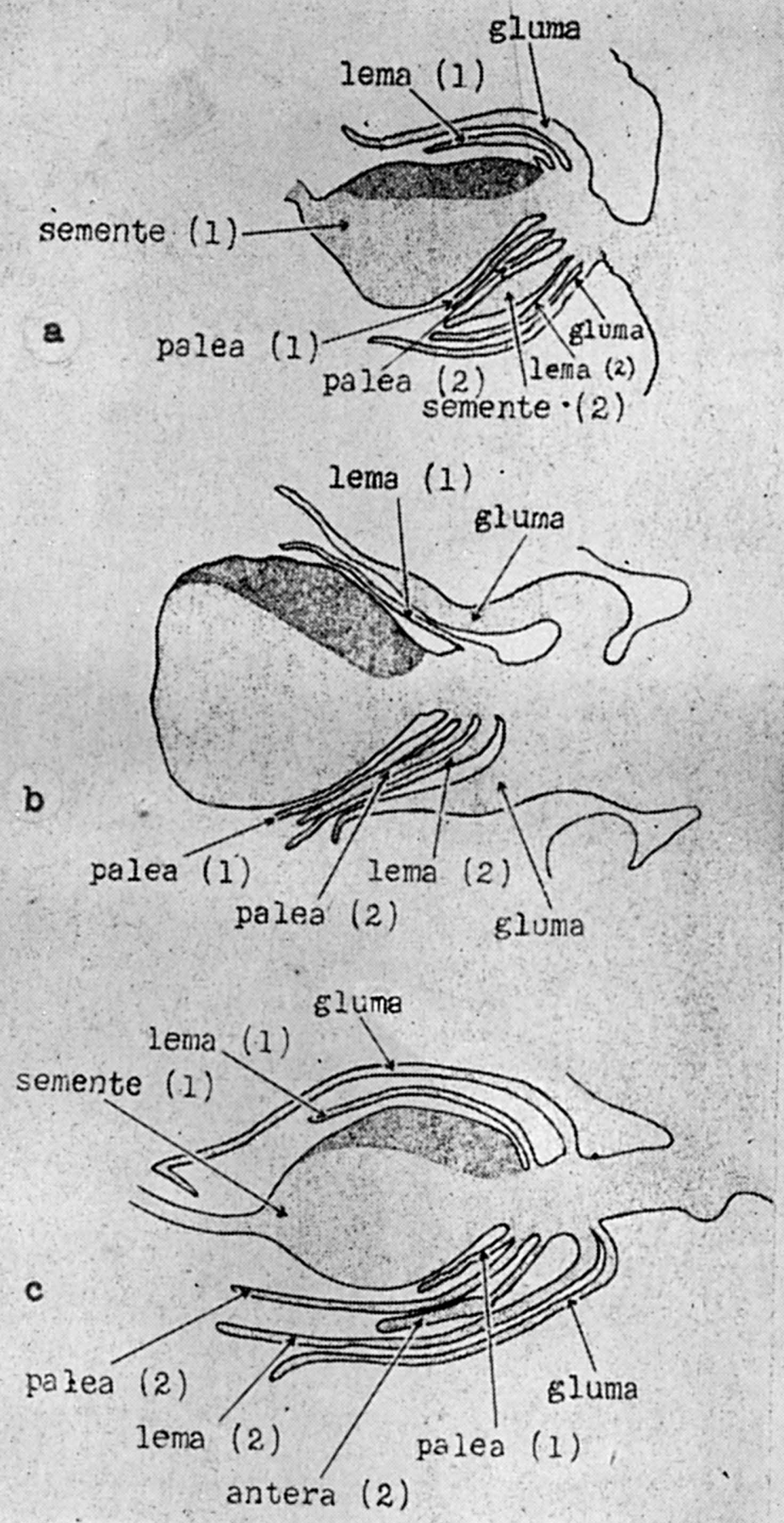

Fig. 4 


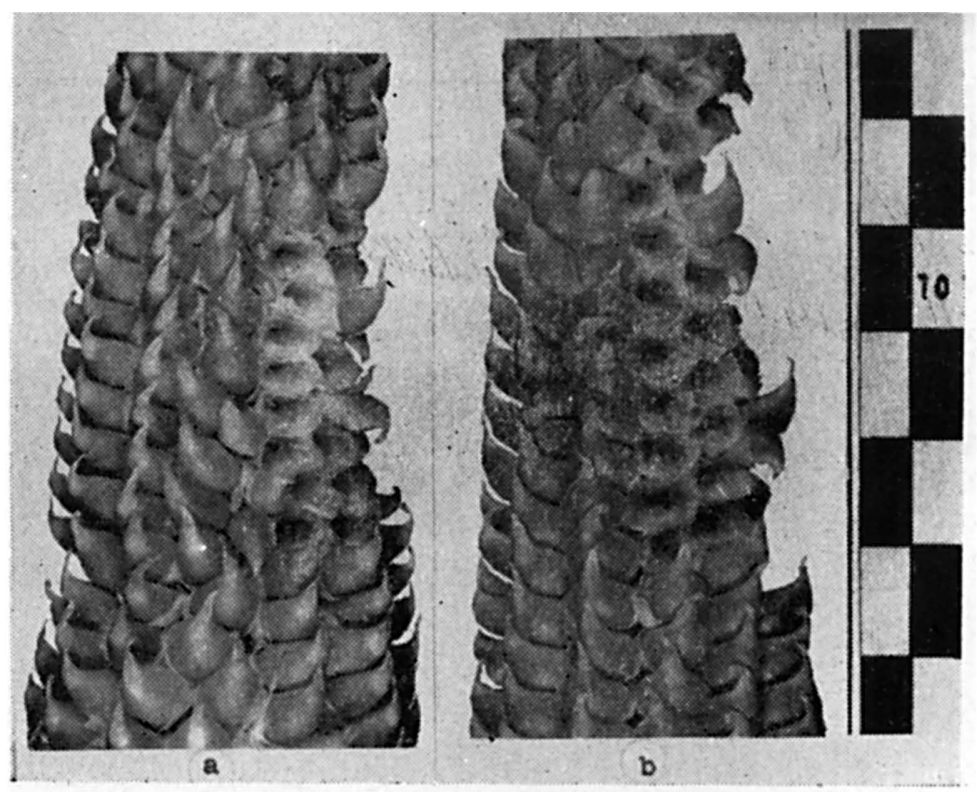

Fig. 5
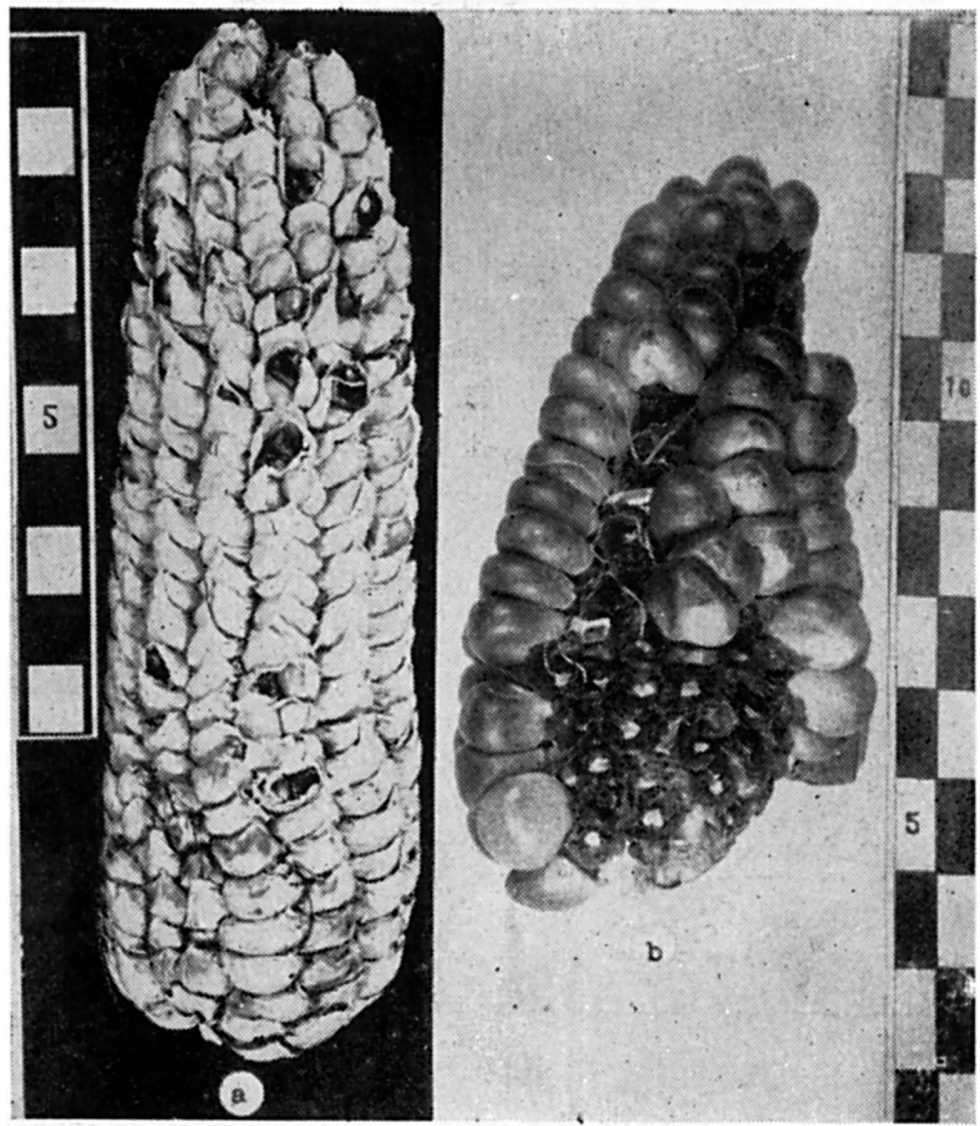

Fig. 6 
número de sementes por espiga tenha qualquer valor em plantaçóes comerclais, pots as sementes menores produzem novos pés, as quais orescem mais atrazados e morosamente, alem do que sáo fracos. Em experiências, entretanto, é possivel conseguir-se mais sementes numa planta mediante uma polinização, assim poupando tempo e espaço.

Estudámos, também, material pertencente ao tipo denominado pelo DR. BRIEGER (1945), "Pipoca Paulista". Neste tipo a disposiçăo dos gráos em fileiras é, de ordinário, muito regular, tornando-se as fileiras ainda mais acentuadas pela curvatura forte das pontas dos grăos, viradas para o ápice da espiga (fig. 1B), Esporadicamente, encontram-se, espigas com um número variável de espiguetas de dois gráos, a ponta de um dirigida para o ápice da espiga e a ponta do outro, para a base.

O desenvolvimento dos grăos irmãos pode ser quase idêntjco (Fig. 5A), porém, é mais comum encontrar-se um grăo normal e o outro pequeno ou mesmo quase abortivo (Fig. 5B). Os grãos pequenos, a primeira vista, assemelham-se as estruturas existentes na base do grão verdadeiro, na flor superior, descritas por WEATHERWAX (1925) como um casa de carpelodia superior (carpellody). Os grãos das espigas que o dr. BRIEGER descobriu são diferentes das estruturas descritas por WEATHERWAX, sendo localizados em flores distintas.

A natureza morfológica dos grãos duplos no milho "Pipoca Pontuda Paulista" é llustrada no desenho da fig. 4C, que inostra tratar-se do mesmo processo já citado para o milho doce Country Gentleman. No desenho as duas flores incluidas nas glumas 1 e 2 sáo bem visiveis, sendo uma abortiva e outra normalmente desenvolvida.

Como acontece no Country Gentleman, a introdução dos grãos adicionais entre os grăos superiores ou normais; força êstes para fora do alinhamento. Isto se evidencia quando comparamos duas espigas no material do Dr. BRIEGER, uma das quais contém o maior número de espiguetas de dois grãos até hoje encontrado nesta variedade, e outra que é normal e típica da variedade (Figs. 1A, 1B).

Outra espiga peculiar, descoberta pelo Dr. BRIEGER, é uma tunicata que frequentemente tem espiguetas ramificando-se de modo a formar duas outras, completas, semelhantemente ao que ocorre no milho ramosa: As espiguetas săo simétricas, viradas para lados opostos, e como somente a flor superior se desenvolve, um dos grãos fica com embriåo è ponta 
opostos aos dos grăos em espiguetas comuns (Fig. 3B). Nesta mesmai espiga, encontramos também espiguetas com as flores inferiores desenvolvidas, uma condiçáo considerada primitiva, tal como no caso do milho ramosa. Isso náo é extraordinário, porque a espiga é descendente do milho tunicata, de Săo Pau1o, cruzado com milho primitiyo dos indios de Mato Grosso.

STURTEVANT (1894, segundo RANDOSPH 1936) já encontrou espiguetas de dois grãos em milho tunicata. Embora raros os casos de aumento de número de grăos em espiguetas de milho tunicata, săo comuns as espigas nas quais, em vez de uma espigueta normal com um grăo, encontra-se um ramo com muitas palhas e faltando flores ou gráos.

Seria mais conveniente considerar que o milho provém de uma gramínea, com ambas as flores funcionais. A posição da flor abortiva serve como uma das caracteristicas principais na divisáo dos grupos "Poaceae" e "Panicaceae" (ARBER 1934), apesar de que o milho pertença ao último grupo um taxonomista correrá o risco de classificar como "Poaceae" certas espigas procedentes da Bolívia, se houver examinado sommente as espigas. Essas espigas raras, encontradas pelo dr. MARTIN CARDENAS săo pequenas e não completamente cobertas de grãos formando-se grãos somente nas flores inferiores. Isto indica ser possivel que as flores superiores amadureçam antes de aparecer 0 pólen, e somente depois as flores inferiores, que se desenvolvem posteriormente, são fertilizadas.

Uma fotografia de uma espiga pequena (Fig. 6A), mas bem granada, de milho boliviano (tipo Culli), coleclonado pelo Dr. MARTIN CARDENAS, mostra que, na mesma espiga; é possivel encontrar espiguetas com grăos procedentes das flores superiores ou das inferiores.

Como antecipáramos, espigas com espiguetas de dois grãos aparecem mais frequentemente no centro de maior variação do milho, e perto do provável centro de origem. Aqui, entretanto, esses tipos são raros nas variedades em que fol feita seleçåo para espigas com fileiras distintas. Nos Andes da Bolivia há tolerância para uma variedade com grãos distribuidos irregularmente e nåo fileiras direitas, e as esplgas com espiguetas de dois grãos (chamadas cuti sara, em Quechua), são usadas como remédio para dores nos pulmóes, concorre para conservar essa característica (CARDENAS e CUTLER 1943). O milho doce Country Gentleman é uma variedade recente, e a distribuição irregular e muito agrupada dos grãos é tolerada porque os grãos são comidos diretamente da espiga, quando o milho é nova e tenro. 
lamentável que muitas pesquisas genéticas năo sejąm acompanhadas por uma descrição das estruturas homólogas na espiga e no pendăo. A maior parte dos gens influindo na formação do pendão também influi na da espiga, e vice-versa. Entre os gens que influem no desenvolvimento da flor inferior figuram o silky 1, silky2, silky 3, alguns gens tassel seed è sorghum tassel (seda 1, seda 2, seda 3 , sementes no pendão tipo sorgo). O maior número desses são recessivos.

Quando o pendão tem grăos, êstes grãos estão nas flores superiores das espiguetas (KEMPTON 1913) como mostrado na figura 4A. Depois de pesquisas feitas com milho Country Genileman, HUELSEN e GIILES (1929) descobriram que seus dados estão de acôrdo com a hipótese de que os dois grăos em cada espigueta resultam da ação de dois pares de gens recessivos pp e p2p2. O gen ou os gens para espiguetas de dois grãos em milho boliviano são também recessivos.

\section{RESUMO}

A. morfologia, ocorrência, utilidade e genética das flores funcionais inferiores em espiguetas de milho, são examinadas ligeiramente. Em regra, somente a flor superior em cada espigueta numa espiga de milho se desenvolve e contém um grão, porém nos exemplos em foco a flor inferior se desenvolve tão bem como a superior.

O embrião no milho geralmente se acha voltado na mesma direção que a ponta da espiga, ao passo que o embriáo do grăo proveniente da flor inferior se volta na direção da base.

São raras, não só na América do Norte e Central, como na maior parte da América do Sul, as espigas nas quais os grăos provêm da flor inferior das espiguetas, constituindo uma exceção o milho doce Country Gentleman, no qual se encontram grãos em ambas as flores na maioria das espiguetas. No Brasil e na Bolivia, entretanto, são mais comuns as espigas com espiguetas de dois grãos. Sendo o milho proveniente da América do Sul, é de esperar-se que se encontrem mais variedades e tipos mais primitivos próximo do centro de origem.

No milho Pipoca Pontudo Paulista, o Dr. BRIEGER encontrou espigas com ambas as flores funcionais em algumas espiguetas. Em alguns casos, ambos os grãos eram de tamanho normal, porém, mals comumente, um dos dois grãos era bem menor que o outro.

Fm espigas encontradas pelo Dr. MARTIN CARDENAS, al. gumas espiguetas apresentam gráos provindos sòmente das 
flores inferiores, uma circunstancia característica do grupo "Poaceae", e năo do "Panicaceae" a que pertence o milho.

Muitos gens que influenciam os característicos do pendão, também influenciam os das espigas. Alguns destes controlam a formação de grăos na flor inferior da espigueta-femea. A maioria dos gens conhecidos como afetando as espiguetas inferiores, são recessivos, tal como no caso das espigas brasileira e boliviana estudadas, e no Country Gentleman.

Um exemplo de espiguetas gêmeas fol encontrado entre o material tunicata do Dr. BRIEGER. Ai, em vez de uma só espigueta, o que é o normal, havia duas espiguetas completas, simétricas, sendo uma em posiçáo oposta ao normal. Os grăos, em ambas, achavam-se na flor superior.

Prosseguem os estudos sobre a espigueta do milho. O Dr. GONÇALVES DRUMOND, da Escola Superior de Viçosa, Minas Gerais, encontrou recentemente algumas espigas de "Cateto", inas quais a flor inferior é funcional e está estudando as mesmas. Parece que o mais interessante material para os novos estudos é o que o Dr. BRIEGER encontrou no seu milho "P1poca Pontudo Paulista, pols há al graus variaveis de desenvolvimento tanto superiores como inferiores.

\section{SUMMARY}

1 - The morphology, occurrence use and genetics of functional lower flowers in spikelets of maize are discussed briefly. Normally only the upper flower in each spikelet of a maize ear develops and bears a grain but in the examples discussed the lower flower develops as well as the upper.

2 - The embryo in maize is usually turned toward the tip of the ear while that of the grain produced from the lower flower is turned toward the base.

3 - In North and Central America and most of South America ears in which grains are borne in the lower flower of the spikelets are rare. One exception is the sweet corn, "Country Gentleman", which bears grains in both flowers of most spikelets. In Brasil and Bolivia, however, ears with two grained spikelets are more common. If maize originated in South America, one would expect to find more varieties, and more primitive types near the center of origin.

4 - In Pointed São Paulo (Brazil) Pop Corn, Dr. BRIE- 
GER found ears in which both flowers developed in some splkelets. In some spikelets both grains were of normal size, but more often either the lower or the upper grain was much smaller.

5 - In ears found by Dr. MARTIN CARDENAS some splkelets bear only grains from the lower flowers, a condition characteristic of the "Poaceae" and not the "Panicaceae", to which maize belogns.

6 - Many genes which influence tassel characters also influence the ears. Some of these control the formation of grains in the lower flower of the female spikelet. Most of the known genes affecting the lower spikelets are recessive, as are those in the Bolivian and Brazilian ears studied, and in "Country Gentleman".

7 - An example of paired spikelets was found in Dr. Brieger's tunicate material. In this case two complete spikelets appear where normally there would be only one. They are symetrical, and one of them thus is in a position opposite to the normal. The grains in both are borne in the upper flower.

8 - Studies on the maize spikelet are being continued. Dr. Gonçalves Drumond of the Escola Superior de Viçosa, Minas Gerais, recently found some ears of "Cateto", the common Brazilian orange flint, in which the lower flower was functional and he is studying this line. The most interesting material for further study appears to be that found by $\mathrm{Dr}$. Brieger in his Pipoca Pontudo Paulista, for here there are varying degrees of development of both the upper and lower grains.

\section{BIBLIOGRAFIA}

1 - ARBER, AGNES, 1934 - The gramineae, a study of Cereal, Bamboo and Grass. 480 pp. Cambridge.

2 - BONNETT, O. P. 1940. - Development of the staminate and pistillate inflorescences of sweet corn. Journ. Agr. Res. 60: 25-37.

3 - BRIEGER, F. G. 1945. Estudos experimentais sobre a origem do milho. Anais da Escola Superior "Luiz de Quelroz". 2: 225-278. 
4 - CARDENAS, MARTIN and HUGH CUTLER. 1943. Dos variaciones interessantes en el malz. Revista de Agricultura, Univ. Autonoma Simon Bollvar, Cochabamba, Bolivia 1: 3-5.

5- HUELSEN, W. A. and M. C. GriLIS' 1929. Inheritance of kernel arrangement in sweet corn. Illinols Agricultural Experiment Station Bull. 320: 299-336.

6 - KEMPTON, JAMES H. - Floral abnormalities in maize 1913.U. S. Bureau Plant Industry Bull. 278: 1-16.

7 - RANDOSPH, L. F. - Developmental morphology of the caryopsis in maize Jorn. Agr. Res. 53 :881-916.

8 - STEWART, A. 1915 - The pistillate spikelet in Zea Mays. Science. 24: 694.

9 - STURTEVANT, G. L. 1894. Notes on maize. Bull. Torrey Bot. Club: 21: 319-343.

10 - WEATHERWAX, P. 1916: - Morphology of the flowers of Zea Mays. Bull. Torrey Club. 43: 127-144.

$\$ 1$ - WEATHERWAX, P. 1925. - Anomalies in maize and its relatives III. Carpellody in maize. Bull. Torrey Botanical Club 52: 167-171.

12 - WEATHERWAX, P. 1935 - The phyllogeny of Zea Mays. American Midland Naturalist. $16: 1-71$. 